\title{
The DELUX study: development of lung volumes during extubation of preterm infants
}

\author{
Leonie Plastina $^{1,3}$, Vincent D. Gaertner (iD ${ }^{1,3 凶}$, Andreas D. Waldmann ${ }^{2}$, Janine Thomann ${ }^{1}$, Dirk Bassler ${ }^{1}$ and Christoph M. Rüegger (iD ${ }^{1}$ \\ (c) The Author(s) 2021
}

\begin{abstract}
OBJECTIVE: To measure changes in end-expiratory lung impedance (EELI) as a marker of functional residual capacity (FRC) during the entire extubation procedure of very preterm infants.

METHODS: Prospective observational study in preterm infants born at 26-32 weeks gestation being extubated to non-invasive respiratory support. Changes in EELI and cardiorespiratory parameters (heart rate, oxygen saturation) were recorded at prespecified events during the extubation procedure compared to baseline (before first handling of the infant).

RESULTS: Overall, 2912 breaths were analysed in 12 infants. There was a global change in EELI during the extubation procedure ( $p$ $=0.029)$. EELI was lowest at the time of extubation [median (IQR) difference to baseline: $-0.30 \mathrm{AU} / \mathrm{kg}(-0.46 ;-0.14)$, corresponding to an FRC loss of $10.2 \mathrm{ml} / \mathrm{kg}(4.8 ; 15.9), p_{\text {adj }}=0.004$ ]. The biggest EELI loss occurred during adhesive tape removal [median change (IQR): $\left.-0.18 \mathrm{AU} / \mathrm{kg}(-0.22 ;-0.07), p_{\text {adj }}=0.004\right]$. EELI changes were highly correlated with changes in the $\mathrm{SpO}_{2} / \mathrm{FiO}_{2} \mathrm{ratio}(r=0.48$, $p<0.001)$. Forty per cent of FRC was re-recruited at the tenth breath after the initiation of non-invasive ventilation $(p<0.001)$. CONCLUSIONS: The extubation procedure is associated with significant changes in FRC. This study provides novel information for determining the optimal way of extubating a preterm infant.
\end{abstract}

Pediatric Research (2022) 92:242-248; https://doi.org/10.1038/s41390-021-01699-w

\section{IMPACT:}

- This study is the first to examine the development of lung volumes during the entire extubation procedure including the impact of associated events.

- The extubation procedure significantly affects functional residual capacity with a loss of approximately $10 \mathrm{ml} / \mathrm{kg}$ at the time of extubation.

- Removal of adhesive tape is the major contributing factor to FRC loss during the extubation procedure.

- Functional residual capacity is regained within the first breaths after initiation of non-invasive ventilation and is further increased after turning the infant into the prone position.

\section{INTRODUCTION}

Although non-invasive modes of ventilation are considered superior to intubation at birth, ${ }^{1}$ approximately $60 \%$ of preterm infants are intubated in the first days of life. ${ }^{2}$ Prolonged endotracheal ventilation can lead to inflammation, tissue damage and the disruption of lung development. ${ }^{3-6}$ To reduce these risks, clinicians aim to extubate preterm infants to non-invasive respiratory support as soon as possible. Still, approximately $40 \%$ of preterm infants develop respiratory failure after extubation and require re-intubation, which is associated with significant morbidity, including increased duration of endotracheal ventilation, airway trauma, feeding difficulties and death. ${ }^{7}$ To avoid such adverse outcomes, prediction of successful extubation is crucial.

A low lung volume after extubation has been identified as an important predictor of extubation failure, emphasizing the relevance of functional residual capacity (FRC) for subsequent clinical outcomes. ${ }^{2,8-11}$ As conventional tools for monitoring lung volumes are inappropriate for repeated measurements in the neonatal setting, the effect of individual interventions on lung volumes during the complete extubation procedure is poorly understood and has never been described so far.

Recently, electrical impedance tomography (EIT) has become available in the neonatal population and allows non-invasive and radiation-free lung volume imaging. ${ }^{12}$ Impedance changes are measured in a cross-sectional slice of the thorax, which is representative for the whole lung in preterm infants. ${ }^{13}$ The use of EIT allows continuous monitoring of changes in ventilation and perfusion, ${ }^{12}$ as demonstrated previously in preterm infants. ${ }^{14,15}$

The primary aim of this study was to describe overall changes in end-expiratory lung impedance (EELI) as a marker of FRC during the entire extubation procedure of preterm infants. Secondary aims were (1) to assess the contribution of specific events during the extubation procedure on EELI, (2) to determine whether EELI changes are associated with cardiorespiratory parameters and (3)

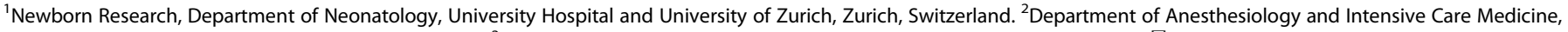
Rostock University Medical Center, Rostock, Germany. ${ }^{3}$ These authors contributed equally: Leonie Plastina, Vincent D. Gaertner. ${ }^{凶}$ email: vincent.gaertner@usz.ch 
Table 1. Baseline demographics and patient characteristics.

\begin{tabular}{lc} 
Patient characteristics & Median (IQR) \\
\hline Perinatal characteristics & $27(27-28)$ \\
\hline Gestational age (completed weeks) & $1140(951-1152)$ \\
\hline Birth weight (g) & $4(33 \%)$ \\
\hline Male, $n$ (\%) & $7(58 \%)$ \\
\hline Complete course of antenatal steroids, $n$ (\%) & $8(6-8)$ \\
\hline APGAR score at 5 min & \\
\hline At extubation & $28(27-30)$ \\
\hline Postmenstrual age (completed weeks) & $3(2-5)$ \\
\hline Age at extubation (days) & $1145(1068-1250)$ \\
\hline Weight at extubation (g) & $12(100 \%)$ \\
\hline Received exogenous surfactant, $n$ (\%) & $1(1-3)$ \\
\hline Days of endotracheal ventilation & \\
\hline Ventilator settings before extubation & \\
\hline Ventilation mode, $n$ (\%) & $10(83 \%)$ \\
\hline PSV-VG & $2(17 \%)$ \\
\hline SIMV-VG & $0.25(0.21-0.27)$ \\
\hline FiO 2 & $8(8-10)$ \\
\hline MAP (mbar) & $4.5(4.4-5.3)$ \\
\hline$V_{\text {T }}$ (ml/kg) & \\
\hline Ventilator settings after extubation & \\
\hline Ventilation mode, $n$ (\%) & $5(7-8)$ \\
\hline NIPPV & \\
\hline nCPAP & \\
\hline MAP (mbar) & \\
\hline & \\
\hline
\end{tabular}

Settings of invasive and non-invasive ventilation were recorded immediately before and immediately after extubation, respectively. PSV pressure support ventilation, SIMV synchronized intermittent mandatory ventilation, $V G$ volume guarantee mode, $\mathrm{FiO}_{2}$ fraction of inspired oxygen, MAP mean airway pressure, $V_{T}$ measured exhaled tidal volume, NIPPV nasal intermittent positive pressure ventilation, nCPAP nasal continuous positive airway pressure.

${ }^{\mathrm{a}}$ For infants $\leq 72 \mathrm{~h}$, birth weight was used as weight at extubation.

to evaluate the development of FRC after initiation of non-invasive ventilation in a breath-by-breath analysis.

\section{METHODS}

\section{Population and intervention}

This was a prospective observational study performed at the neonatal intensive care unit of the University Hospital Zurich (Switzerland). Data were collected as part of a six-month quality control period between August 2020 and January 2021 to improve the extubation procedure in our unit. The Regional Ethics Committee of the Canton Zurich confirmed that this study meets the requirements for quality assurance/audit projects (Req-2020-00929) and, therefore, no informed parental consent was necessary. Infants were eligible for inclusion if they were born between $26^{0 / 7}$ and $31^{6 / 7}$ weeks gestational age, had no malformation that could impede regular lung aeration, were not directed for palliative care, and had a planned elective extubation.

We did not predefine any criteria or devices, and extubation was performed at the clinician's discretion alone. Infants were intubated nasally and the endotracheal tube was fastened to the infant's forehead and cheeks using adhesive tape (see Supplementary Fig. S1). During endotracheal ventilation, Dräger Babylog ${ }^{\circledR}$ VN500 ventilators (Drägerwerk AG, Lübeck, Germany) were used. Non-invasive respiratory support was either ventilator-generated (Babylog ${ }^{\circledR}$ VN500) or flow-driver-generated (fabian Therapy evolution; Acutronic Medical Systems AG, Hirzel, Switzerland). A textile electrode belt with 32 electrodes was fastened at the nipple level when the infant was turned to the supine position before extubation and EIT data were recorded with the LuMon ${ }^{\text {TM }}$ System (SenTec AG, Landquart, Switzerland) at a frame rate of $50.86 \mathrm{~Hz} .{ }^{16}$

According to local standards, infants $<28$ weeks were extubated to nonsynchronized nasal intermittent positive pressure ventilation and infants $\geq 28$ weeks were extubated to nasal continuous positive airway pressure (CPAP). Settings were not mandated, and clinicians could individualize care. Patients received a loading dose of $20 \mathrm{mg} / \mathrm{kg}$ caffeine citrate before extubation to increase respiratory drive. All patients were extubated in the supine position and turned prone when the nasal interface (appropriately sized binasal prongs or nasal mask) was secured in place and the infant was stable. Tracheal suctioning before extubation was performed at the clinician's discretion.

\section{Data collection}

Patient characteristics and the level of respiratory support before, during and after the extubation procedure were recorded. EIT data were recorded continuously, and predefined events were timestamped. Heart rate (HR) and oxygen saturation $\left(\mathrm{SpO}_{2}\right)$ were measured using a Masimo pulse oximeter with a 2-s averaging time (Masimo Radical 7, Masimo Cooperation, Irvine $(\mathrm{CA})$ and recorded with the NewLifeBox ${ }^{\mathrm{TM}}$ recording system (Advanced Life Diagnostics UG, Weener, Germany) with two datapoints per second. Fraction of inspired oxygen $\left(\mathrm{FiO}_{2}\right)$ and exhaled tidal volumes $\left(V_{T}\right)$ before extubation were extracted from the local patient data management system (Metavision, iMDsoft ${ }^{\circledR}$, Tel Aviv, Israel). Patients were video-recorded to accurately correlate events with EIT data.

\section{Data analysis}

Clinical, physiological and EIT data were extracted over a timeframe of $30 \mathrm{~s}$ for the following predefined events: immediately before first handling of the infant (baseline), tracheal suctioning (suction), start and end of adhesive tape removal (adhesive tape begin and adhesive tape end), pulling the endotracheal tube (extubation), initiation of non-invasive ventilation (NIV), immediately before and after turning the infant to prone position (supine and prone, respectively), and $10 \mathrm{~min}$ after turning to prone position $\left(\right.$ prone $\left._{10}\right)$. For each event $30 \mathrm{~s}$ of artefact-free tidal ventilation were extracted. For interventions (suction, adhesive tape begin, adhesive tape end, extubation and NIV) the collected data were divided into 15-s timeframes before and after the event to assess changes occurring during the respective interventions. If an event took place within the 15-s timeframe of a previous event, data were included in both events.

EIT data were extracted and analysed using ibeX (version 1.4, SenTec AG, Landquart, Switzerland). First, vendor-provided predefined anatomical lung regions were projected into the EIT image and EIT signals outside these regions were excluded. ${ }^{17-19}$ Second, EIT signals were extracted and normalized for body weight. Third, the EELI was calculated in arbitrary units per kilogram (AU/kg) for each predefined event. Fourth, changes in EELI were calculated at each event compared to baseline ( $\Delta$ EELI). Finally, we calculated the tidal volume in $\mathrm{AU} / \mathrm{kg}$ by measuring EIT signal changes during each inflation provided by the ventilator at baseline (i.e. endinspiratory minus end-expiratory lung impedance; $V_{T-E T T}$. We then correlated these values to the exhaled tidal volume in millilitre per kilogram $(\mathrm{ml} / \mathrm{kg})$ measured by the ventilator at the same timepoint to calculate relative changes of FRC $\left(V_{\mathrm{T}}\right)$.

\section{Outcomes}

First, we evaluated overall changes in EELI during the entire extubation procedure and then assessed the contribution of each predefined event to changes in EELI. Second, we analysed changes in $\mathrm{SpO}_{2}, \mathrm{FiO}_{2}$ and $\mathrm{HR}$ at each of the events and correlated the results to changes in EELI. And finally, we assessed EELI changes within the first ten breaths after initiation of non-invasive ventilation in a breath-by-breath analysis.

\section{Statistical analysis}

Data were analysed using R statistics (version 3.6.1). ${ }^{20}$ Normal distribution was assessed using the Shapiro-Wilks test. Normally distributed data are presented as mean and standard deviation (SD). Non-parametric data are presented as median and interquartile range (IQR). Global changes in EELI, $\mathrm{HR}, \mathrm{SpO}_{2}$ and $\mathrm{SpO}_{2} / \mathrm{FiO}_{2}$ ratio over all pre-specified events were assessed using a Friedman's type Skillings-Mack test statistic which tests the global difference in medians over time and provides robust results in case of missing data. ${ }^{21}$ In case of a significant global difference over time, post hoc analyses were performed using paired Wilcoxon tests, corrected for 


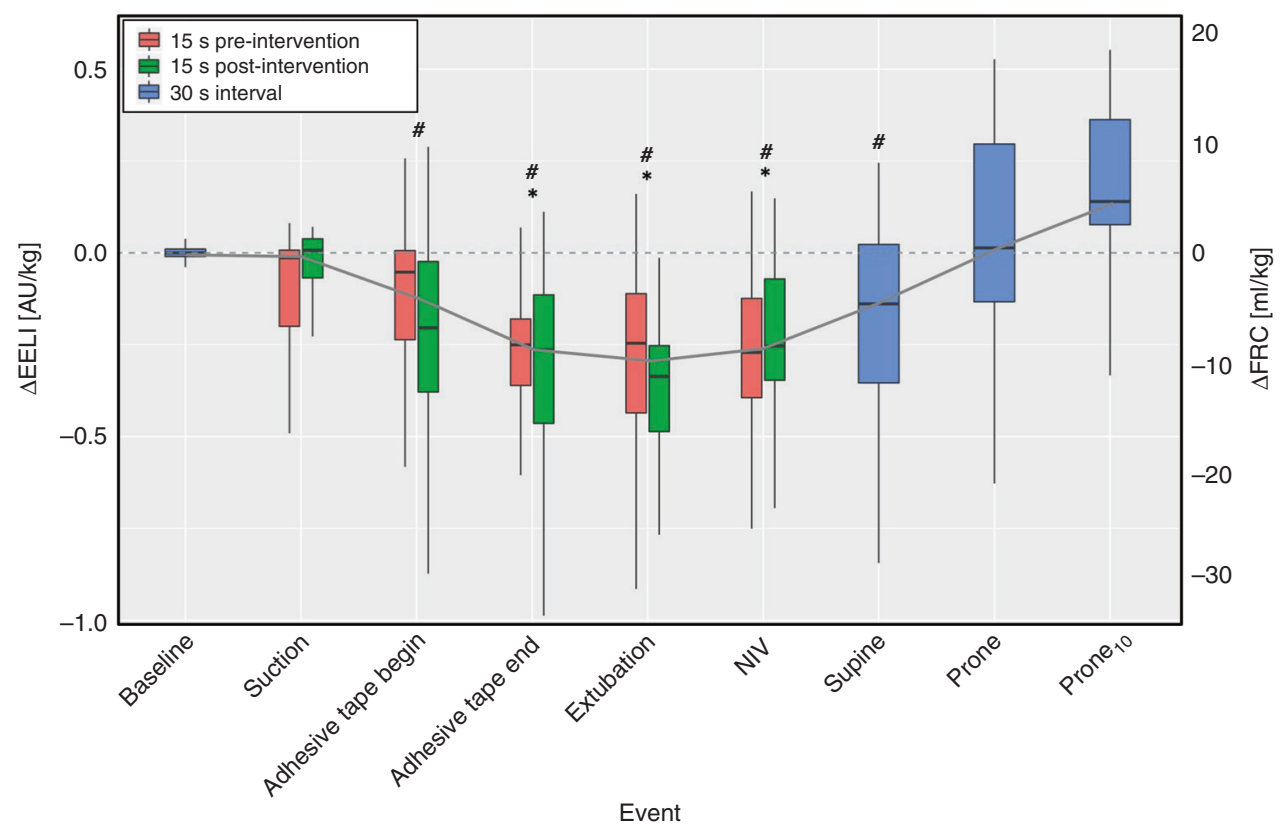

Fig. 1 Development of $\Delta E E L I$ during the extubation process. Red and green boxplots show the $15 \mathrm{~s}$ before and after the respective intervention and blue boxplots show results for 30-s intervals without intervention. Overall, $\Delta$ EELI changed significantly over time (Friedman's type Skillings-Mack test: $p=0.029$ ). Asterisks and hashtags indicate significant differences in single comparisons of $\Delta \mathrm{EELI}$ after correction for multiple testing: ${ }^{*}=$ compared to baseline; \# = compared to prone ${ }_{10}$. Detailed post hoc comparisons can be found in Supplementary Table S1. $\Delta \mathrm{EELI}=$ change in end-expiratory lung impedance compared to baseline, $\mathrm{AU} / \mathrm{kg}=$ arbitrary units per kilogram, $\Delta \mathrm{FRC}=\mathrm{change}$ in functional residual capacity compared to baseline, $\mathrm{ml} / \mathrm{kg}=$ millilitre per kilogram, NIV = initiation of non-invasive ventilation after extubation, prone $_{10}=$ measurement after $10 \mathrm{~min}$ in the prone position.

Table 2. Changes in EELI and FRC compared to baseline (on the left) and compared to the previous event (on the right).

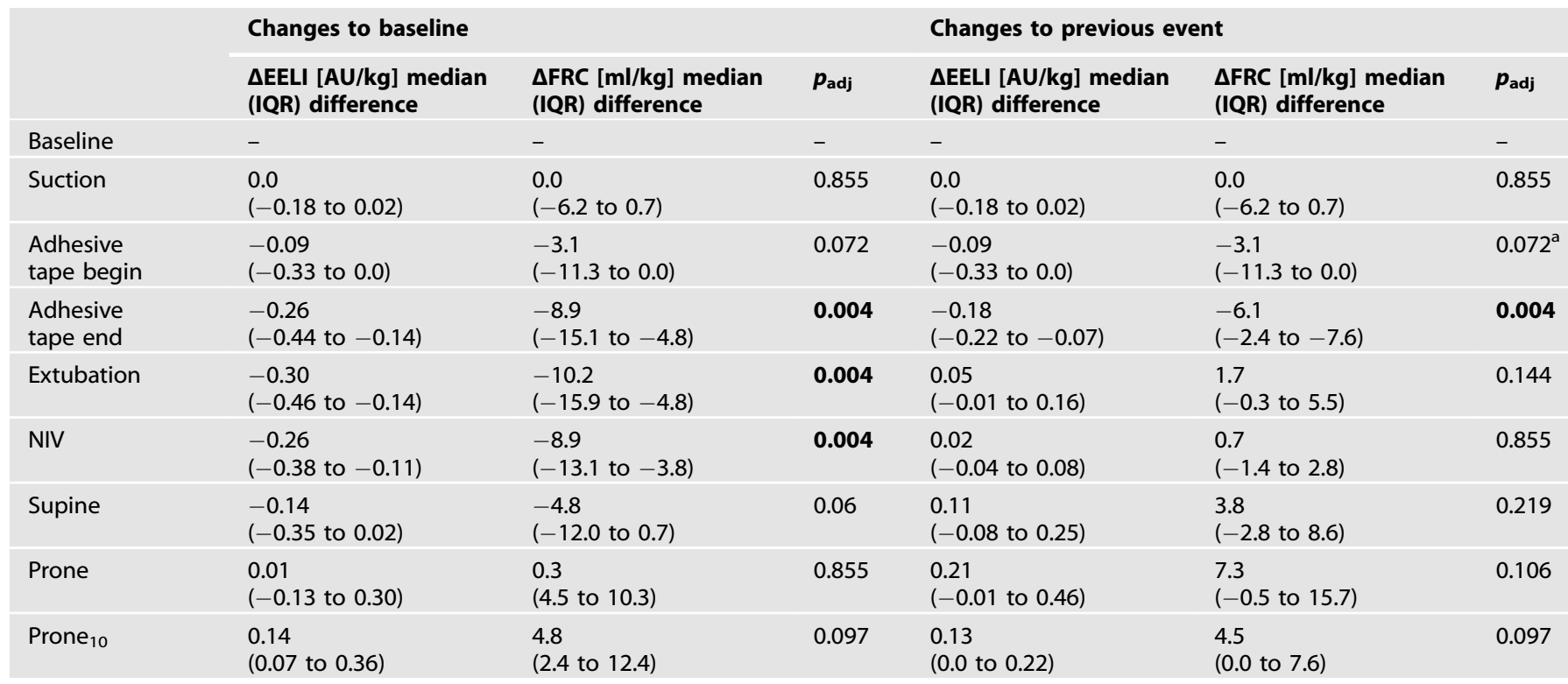

$P$ values are corrected for multiple testing using the Bonferroni-Holm method. Significant changes are indicated in bold. $\triangle E E L I=$ change in end-expiratory lung impedance compared to baseline, $A U / \mathrm{kg}=$ arbitrary units per kilogram, $\triangle F R C=$ change in functional residual capacity compared to baseline, $\mathrm{m} / \mathrm{kg}=$ millilitre per kilogram, NIV = initiation of non-invasive ventilation after extubation, prone $10=$ measurement after $10 \mathrm{~min}$ in the prone position.

a Compared to baseline as not all infants were suctioned endotracheally.

multiple comparisons using the Bonferroni-Holm method. Changes in EELI around an event (e.g. before vs after extubation) were assessed using a paired Wilcoxon test. Correlation was assessed using Spearman's correlation. Adjusted $p$ values $<0.05$ were considered statistically significant.

\section{RESULTS}

\section{Population}

Seventeen infants were extubated during the study period and two of the extubations happened accidentally. Three of the 


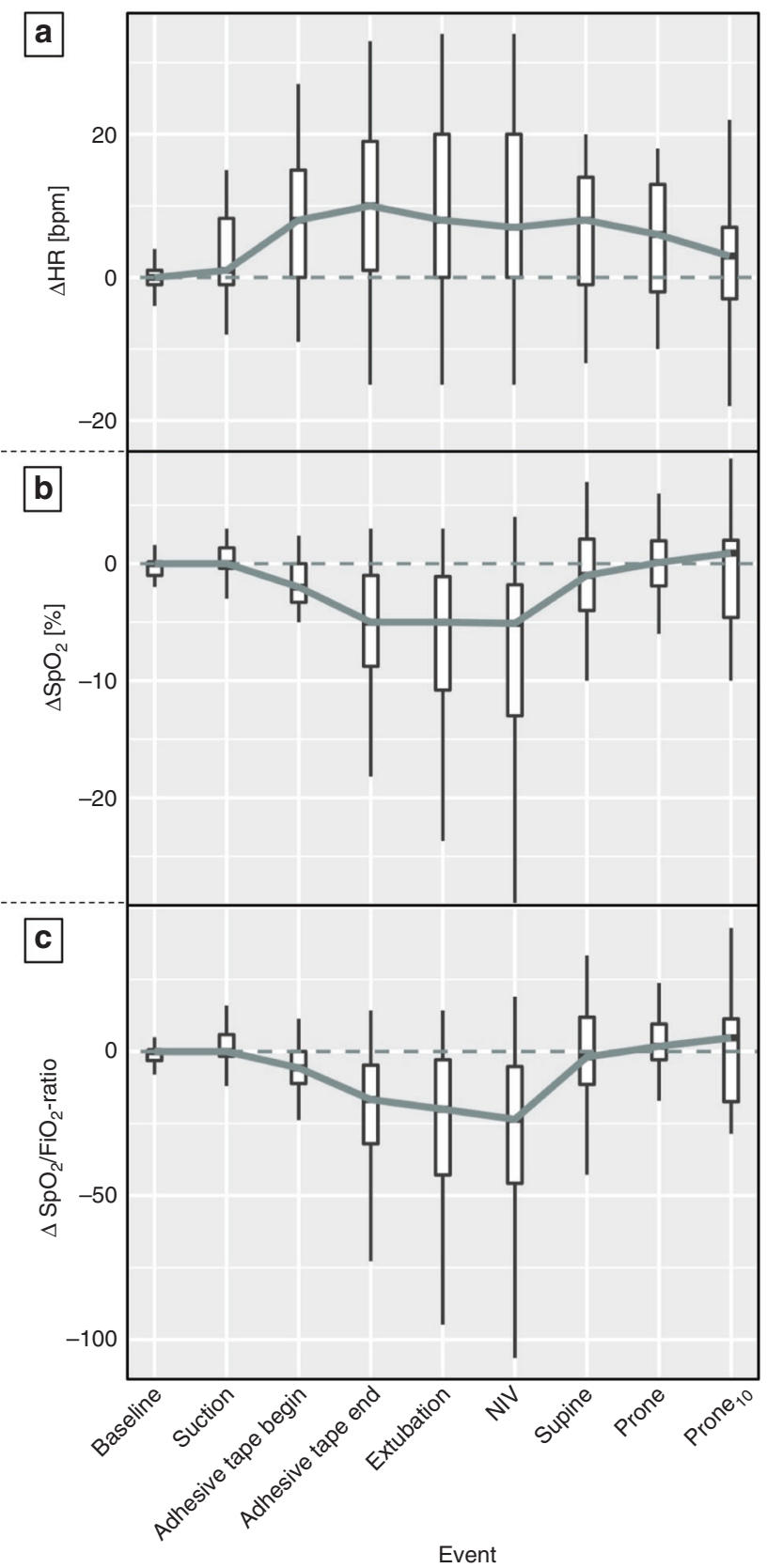

Fig. 2 Development of HR (Panel a), $\mathrm{SpO}_{2}$ (Panel b), and $\mathrm{SpO}_{2} /$ $\mathrm{FiO}_{2}$ ratio (Panel c) during the extubation procedure. Overall, $\mathrm{SpO}_{2}$ changed significantly $(p=0.005)$, while $\mathrm{HR}(p=0.08)$ and $\mathrm{SpO}_{2} / \mathrm{FiO}_{2}$ ratio $(p=0.12)$ showed no global changes (assessed using Friedman's type Skillings-Mack test). $H R=$ heart rate, $b p m=$ beats per minute, $\mathrm{SpO}_{2}=$ peripheral oxygen saturation, $\mathrm{FiO}_{2}=$ fraction of inspired oxygen, $N I V=$ initiation of non-invasive ventilation after extubation, prone $_{10}=$ measurement after $10 \mathrm{~min}$ in the prone position.

remaining 15 extubations occurred during the night where no researcher was available, leaving 12 infants for analysis. Overall, 101 events comprising 2912 breaths were analysed. Patient characteristics are shown in Table 1.

\section{Timing of extubation procedure}

The whole extubation procedure (baseline to prone) took a median (IQR) of $18(13-23) \mathrm{min}$ and the decisive period from adhesive tape begin to NIV took $2.3(1.7-2.8)$ min (see Supplementary Table S1).
Changes in lung volumes during the extubation procedure

There was a significant change in EELI during the extubation procedure (Friedman's test, $p=0.029$ ), which was attributable to two events: Compared to baseline, EELI was significantly lower at adhesive tape end, extubation, and NIV (all $p<0.05$ ). At prone ${ }_{10}$, EELI was significantly higher compared to adhesive tape begin, adhesive tape end, extubation, NIV and supine (all $p<0.05$; see Fig. 1, Table 2 and Supplementary Table S2 for detailed results).

Median (IQR) $V_{\text {T-EIT }}$ of $0.13 \mathrm{AU} / \mathrm{kg}(0.10-0.15)$ corresponded to a $V_{\mathrm{T}}$ of $4.5 \mathrm{ml} / \mathrm{kg}$ (4.4-5.3). At extubation, EELI was significantly lower than at baseline [median (IQR): $-0.30 \mathrm{AU} / \mathrm{kg}(-0.46$ to -0.14$)$, corresponding to an FRC loss of $10.2 \mathrm{ml} / \mathrm{kg}$ (4.8-15.9), $p_{\text {adj }}=$ 0.004]. Loss in EELI between $15 \mathrm{~s}$ before and $15 \mathrm{~s}$ after extubation was not statistically significant [median difference (IQR): $-0.08 \mathrm{AU} /$ $\mathrm{kg}(-0.15$ to 0.0$\left.), p_{\text {adj }}=0.077\right]$. The biggest decrease in EELI occurred between adhesive tape begin and adhesive tape end $\left(p_{\text {adj }}=0.004\right)$ and the biggest increase occurred between supine and prone ( $p_{\text {adj }}=0.106$; see Table 2$)$.

In two infants, EELI did not reach baseline levels at prone ${ }_{10}$ (see Supplementary Fig. S2): one of them developed a pneumothorax requiring re-intubation $50 \mathrm{~h}$ after extubation and the other was relatively mature at 31 completed weeks gestation without further complications.

\section{Changes in clinical parameters during the extubation procedure}

Development of $\mathrm{HR}, \mathrm{SpO}_{2}$ and $\mathrm{SpO}_{2} / \mathrm{FiO}_{2}$ ratio are shown in Fig. 2 . There was a significant change in $\mathrm{SpO}_{2}$ (Friedman's test, $p=$ 0.006), mainly attributable to a decrease at adhesive tape end, extubation and NIV (see Fig. $2 \mathrm{~b}$ and Supplementary Table S3). There was a strong correlation of $\Delta \mathrm{EELI}$ with $\Delta \mathrm{SpO}_{2}(r=0.51, p<$ $0.001)$ and $\Delta \mathrm{SpO}_{2} / \mathrm{FiO}_{2}$ ratio $(r=0.48, p<0.001)$ but not with $\Delta \mathrm{HR}$ $(r=-0.18, p=0.10)$.

\section{Breath-by-breath analysis after initiation of non-invasive ventilation}

Thirty-nine per cent of FRC loss during extubation could be regained within the first ten breaths after initiation of non-invasive ventilation [median (IQR) EELI increase at the tenth breath: 0.12 $\mathrm{AU} / \mathrm{kg}(0.07-0.15)$, corresponding to FRC increase of $4.0 \mathrm{ml} / \mathrm{kg}$ (2.3-5.3); $p<0.001$ ] (Fig. 3).

\section{DISCUSSION}

This study demonstrated that lung volumes decreased significantly during the extubation procedure of very preterm infants using EIT. Evaluating pre-specified events during the extubation procedure, we showed that adhesive tape removal is the major factor contributing to FRC loss during extubation and that turning the infant prone is helpful in re-establishing FRC. Changes in FRC were highly correlated with changes in $\mathrm{SpO}_{2}$ and $\mathrm{SpO}_{2} / \mathrm{FiO}_{2}$ ratio but not with HR. Finally, we could demonstrate that alveolar recruitment started with the first breaths after application of the non-invasive interface.

We described changes in FRC during the complete extubation procedure with lowest values at the time of extubation. We had expected a decrease in FRC but the magnitude of FRC loss (approximately $10 \mathrm{ml} / \mathrm{kg}$ ) was higher than anticipated. This is twice a regular $V_{T},{ }^{22-24}$ and approximately $40 \%$ of the FRC of preterm infants at 44 weeks postmenstrual age $(21-24 \mathrm{ml} / \mathrm{kg}$ measured by multiple breath washout). ${ }^{25,26}$ While the conversion of EIT signal changes to $\mathrm{ml} / \mathrm{kg}$ has limitations in adults, ${ }^{27,28}$ changes in newborns are representative of the whole lung. ${ }^{13}$ Opposed to other diagnostic tools such as respiratory inductance plethysmography, EIT cannot measure absolute intrapulmonary lung volumes and, therefore, absolute numbers still have to be interpreted cautiously. However, we based our calculations on the ratio of $V_{\mathrm{T}}$ measurements from the ventilator and from the EIT 

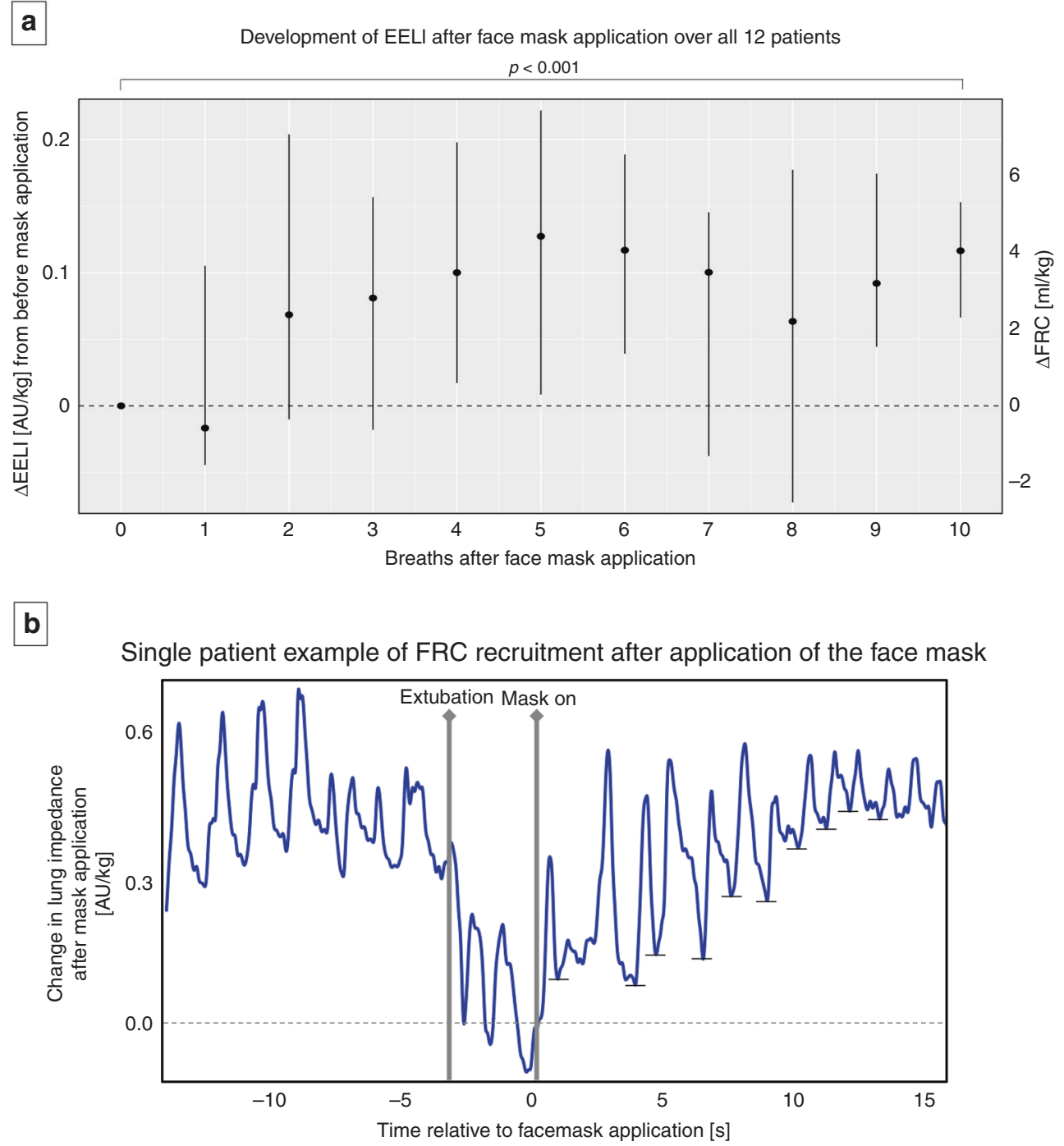

Fig. 3 Breath-by-breath analysis of the first ten breaths after initiation of non-invasive ventilation. a Changes in EELI over the first ten breaths after initiation of non-invasive ventilation. $\mathbf{b}$ Changes in lung impedance of an individual patient where the nasal interface was applied quickly after extubation and who responded well to initiation of non-invasive ventilation with a gradual increase in FRC to the level immediately before extubation. Small horizontal lines at the end of each breath indicate the level of end-expiratory lung impedance (EELI).

device which are known to be correlating strongly. ${ }^{29}$ While this approach is limited in its generalizability, our data clearly show a loss in FRC of considerable magnitude which may contribute to physiological instability during and after extubation. This is underlined in the strong correlation of $\Delta \mathrm{EELI}$ with $\Delta \mathrm{SpO}_{2}$ and $\Delta \mathrm{SpO}_{2} / \mathrm{FiO}_{2}$ ratio in our study.

So far, no study evaluated specific events during the extubation procedure. We now demonstrated that adhesive tape removal was the major factor contributing to FRC loss before extubation, possibly associated with two factors: (1) increased infant movements and concomitant thoracic muscle contractions due to pain which may have resulted in a decreased lung volume; (2) manipulation and movement of the endotracheal tube during adhesive tape removal which may have contributed to increased leak and subsequent FRC loss. Thus, we speculate that re-recruiting atelectatic lung areas before removing the endotracheal tube may be beneficial and propose two potential strategies to achieve rerecruitment: (1) leaving more time between end of adhesive tape removal and extubation and (2) increasing the mean airway pressure (e.g. by 1-2 mbar) after adhesive tape removal but before pulling the endotracheal tube. However, these hypotheses need to be tested in clinical trials before conclusions can be drawn.
After extubation, FRC increased gradually and reached levels higher than during endotracheal ventilation after turning the infant into the prone position. In fact, only two infants did not achieve FRC values as high as prior to extubation, one of which developed a pneumothorax and required re-intubation. Similar to previous reports on the detection of pneumothoraces in preterm infants, ${ }^{30,31}$ this may indicate a benefit of measuring EIT changes during extubation. Prone positioning is associated with an increase in FRC, ${ }^{14,32}$ lung compliance and oxygenation, ${ }^{33-35}$ probably due to a larger area of gas exchange. These factors may have contributed to a higher FRC after extubation. Thus, we speculate that extubating infants in the prone position may improve respiratory stability. However, this hypothesis needs to be tested in further trials.

Finally, re-recruitment of collapsed lung areas after extubation started with the initiation of non-invasive ventilation. Approximately $40 \%$ of FRC loss was regained within the first ten breaths after application of a nasal interface. Immediately after birth most breaths of preterm infants are characterized by expiratory braking manoeuvres, ${ }^{36}$ which may assist in establishing and maintaining FRC after birth. ${ }^{19}$ We speculate that similar mechanisms may also have contributed to re-recruitment of FRC after extubation. This 
finding highlights the importance of immediate initiation of noninvasive ventilation after extubation. We propose two potential means to reduce FRC loss in selected high-risk situations: (1) by pulling back the endotracheal tube only marginally and using it as nasopharyngeal tube temporarily until successful transition to non-invasive ventilation or (2) providing pre-extubation CPAP ("PrePAP") by establishing non-invasive ventilation before pulling the endotracheal tube (e.g. via nasal mask or via modified pacifier ${ }^{37}$ depending on route of intubation). However, these ideas need to be tested in adequately powered trials before implementation into clinical practice.

Our study has various limitations: First, we only had a small sample size which may have contributed to the lack of significant changes in $\mathrm{HR}$ or $\mathrm{SpO}_{2} / \mathrm{FiO}_{2}$ ratio. However, evaluating approximately 3000 breaths, we could reliably demonstrate changes in EELI during extubation, thereby laying the foundation for subsequent clinical trials. Second, this was an observational study where we chose a pragmatic approach and left all decisions to the treating physicians. This may have resulted in heterogeneity but increased generalizability to clinical practice. Third, we did not focus on clinical outcomes. Based on our data, EIT data may potentially be used as a predictor for extubation failure but this needs to be confirmed in larger studies. Fourth, artefacts induced by body movement or interference with medical devices can affect accuracy of EIT data, ${ }^{38,39}$ but changes in lung volumes over time are known to be accurate in modern devices. ${ }^{12}$ Our findings are useful for the development of future trials which may ultimately reduce re-intubation and mechanical ventilation, thereby potentially reducing relevant long-term morbidity and mortality in preterm infants. ${ }^{4,40,41}$ Fourth, this was a single-centre study limiting the generalizability of our findings, particularly as extubation procedures vary between neonatal units.

\section{CONCLUSION}

In this study, we demonstrated that lung volumes decreased significantly during the extubation procedure of very preterm infants. Removal of adhesive tape is the major factor contributing to FRC loss during extubation and turning the infant prone after extubation is helpful in re-establishing FRC. Changes in FRC were highly correlated with changes in $\mathrm{SpO}_{2}$ and $\mathrm{SpO}_{2} / \mathrm{FiO}_{2}$ ratio. Finally, re-recruitment of FRC starts with the first breaths after initiation of non-invasive respiratory support. This observational study provides relevant information for designing new trials investigating the optimal way of extubating a preterm infant.

\section{DATA AVAILABILITY}

De-identified individual participant data, study protocols and statistical analysis codes are available from 3 months to 10 years following article publication to researchers who provide a methodologically sound proposal, with approval by an independent review committee ("learned intermediary"). Proposals should be directed to vincent. gaertner@usz.ch to gain access. Data requestors will need to sign a data access or material transfer agreement approved by USZ.

\section{REFERENCES}

1. Subramaniam, P., Ho, J. J. \& Davis, P. G. Prophylactic nasal continuous positive airway pressure for preventing morbidity and mortality in very preterm infants. Cochrane Database Syst. Rev. CD001243 (2016).

2. Dargaville, P. A. et al. Incidence and outcome of CPAP failure in preterm infants. Pediatrics 138, e20153985-e20153985 (2016).

3. Klinger, G. et al. Perinatal risk factors for bronchopulmonary dysplasia in a national cohort of very-low-birthweight infants. Am. J. Obstet. Gynecol. 208, 115. e1-e9 (2013)

4. Isayama, T., Iwami, H., McDonald, S. \& Beyene, J. Association of noninvasive ventilation strategies with mortality and bronchopulmonary dysplasia among preterm infants: a systematic review and meta-analysis. JAMA 316, 611-624 (2016).
5. Laughon, M. M. et al. Prediction of bronchopulmonary dysplasia by postnatal age in extremely premature infants. Am. J. Respir. Crit. Care Med. 183, 1715-1722 (2011).

6. Thébaud, B. et al. Bronchopulmonary dysplasia. Nat. Rev. Dis. Prim. 5, 78 (2019).

7. Ammari, A. et al. Variables associated with the early failure of nasal CPAP in very low birth weight infants. J. Pediatr. 147, 341-347 (2005).

8. Balsan, M. J., Jones, J. G., Watchko, J. F. \& Guthrie, R. D. Measurements of pulmonary mechanics prior to the elective extubation of neonates. Pediatr. Pulmonol. 9, 238-243 (1990).

9. Szymankiewicz, M., Vidyasagar, D. \& Gadzinowski, J. Predictors of successful extubation of preterm low-birth-weight infants with respiratory distress syndrome. Pediatr. Crit. Care Med. 6, 44-49 (2005).

10. Kavvadia, V., Greenough, A. \& Dimitriou, G. Prediction of extubation failure in preterm neonates. Eur. J. Pediatr. 159, 227-231 (2000).

11. Kamlin, C. O. F., Davis, P. G. \& Morley, C. J. Predicting successful extubation of very low birthweight infants. Arch. Dis. Child Fetal Neonatal Ed. 91, F180-F183 (2006).

12. Frerichs, I. et al. Chest electrical impedance tomography examination, data analysis, terminology, clinical use and recommendations: consensus statement of the TRanslational EIT developmeNt stuDy group. Thorax 72, 83-93 (2017).

13. van der Burg, P. S., Miedema, M., de Jongh, F. H., Frerichs, I. \& van Kaam, A. H. Cross-sectional changes in lung volume measured by electrical impedance tomography are representative for the whole lung in ventilated preterm infants. Crit. Care Med. 42, 1524-1530 (2014).

14. van der Burg, P. S., Miedema, M., de Jongh, F. H., Frerichs, I. \& van Kaam, A. H. Changes in lung volume and ventilation following transition from invasive to noninvasive respiratory support and prone positioning in preterm infants. Pediatr. Res. 77, 484-488 (2015).

15. van der Burg, P. S., de Jongh, F. H., Miedema, M., Frerichs, I. \& van Kaam, A. H. effect of minimally invasive surfactant therapy on lung volume and ventilation in preterm infants. J. Pediatr. 170, 67-72 (2016).

16. Sophocleous, L. et al. Clinical performance of a novel textile interface for neonatal chest electrical impedance tomography. Physiol. Meas. 39, 044004 (2018).

17. Tingay, D. G., Waldmann, A. D., Frerichs, I., Ranganathan, S. \& Adler, A. Electrical impedance tomography can identify ventilation and perfusion defects: a neonatal case. Am. J. Respir. Crit. Care Med. 199, 384-386 (2019).

18. Gaertner, V. et al. Transmission of oscillatory volumes into the preterm lung during noninvasive high-frequency ventilation. Am. J. Respir. Crit. Care Med. 203, 998-1005 (2021).

19. Tingay, D. G. et al. Imaging the respiratory transition at birth: unravelling the complexities of the first breaths of life. Am. J. Respir. Crit. Care Med. 204, 82-94 (2021).

20. R Core Team. R: A Language and Environment for Statistical Computing (R Foundation for Statistical Computing, 2013).

21. Skillings, J. H. \& Mack, G. A. On the use of a Friedman-type statistic in balanced and unbalanced block designs. Technometrics 23, 171 (1981).

22. Mian, Q. N. et al. Tidal volumes in spontaneously breathing preterm infants supported with continuous positive airway pressure. J. Pediatr. 165, 702-6.e1 (2014).

23. Pickerd, N., Williams, E. M., Watkins, W. J. \& Kotecha, S. Tidal breathing in preterm infants receiving and weaning from continuous positive airway pressure. $J$. Pediatr. 164, 1058-1063.e1 (2014).

24. Blank, D. A. et al. Respiratory changes in term infants immediately after birth. Resuscitation 130, 105-110 (2018).

25. Latzin, P. et al. Lung volume, breathing pattern and ventilation inhomogeneity in preterm and term infants. PLOS ONE 4, e4635 (2009).

26. Riedel, T., Kyburz, M., Latzin, P., Thamrin, C. \& Frey, U. Regional and overall ventilation inhomogeneities in preterm and term-born infants. Intensive Care Med. 35, 144-151 (2009).

27. Karsten, J., Stueber, T., Voigt, N., Teschner, E. \& Heinze, H. Influence of different electrode belt positions on electrical impedance tomography imaging of regional ventilation: a prospective observational study. Crit. Care 20, 3 (2016).

28. Frerichs, I., Hahn, G. \& Hellige, G. Thoracic electrical impedance tomographic measurements during volume controlled ventilation-effects of tidal volume and positive end-expiratory pressure. IEEE Trans. Med. Imaging 18, 764-773 (1999).

29. Sosio, S. et al. A calibration technique for the estimation of lung volumes in nonintubated subjects by electrical impedance tomography. Respiration 98, 189-197 (2019).

30. Miedema, M., Frerichs, I., de Jongh, F. H. C., van Veenendaal, M. B. \& van Kaam, A. $H$. Pneumothorax in a preterm infant monitored by electrical impedance tomography: a case report. Neonatology 99, 10-13 (2011).

31. Miedema, M. et al. Electrical impedance tomography identifies a distinct change in regional phase angle delay pattern in ventilation filling immediately prior to a spontaneous pneumothorax. J. Appl. Physiol. 127, 707-712 (2019).

32. Kumar, P., Leonidas, J. C., Ashtari, M., Napolitano, B. \& Steele, A. M. Comparison of lung area by chest radiograph, with estimation of lung volume by helium dilution 
during prone and supine positioning in mechanically ventilated preterm infants: a pilot study. Pediatr. Pulmonol. 40, 219-222 (2005).

33. Wagaman, M. J. et al. Improved oxygenation and lung compliance with prone positioning of neonates. J. Pediatr. 94, 787-791 (1979).

34. Gouna, G. et al. Positioning effects on lung function and breathing pattern in premature newborns. J. Pediatr. 162, 1133-1137, 1137.e1 (2013).

35. Rivas-Fernandez, M. et al. Infant position in neonates receiving mechanical ventilation. Cochrane Database Syst. Rev. 11, CD003668 (2016).

36. te Pas, A. B. et al. Breathing patterns in preterm and term infants immediately after birth. Pediatr. Res. 65, 352-356 (2009).

37. Carlisle, H. R., Kamlin, C. O. F., Owen, L. S., Davis, P. G. \& Morley, C. J. Oral continuous positive airway pressure (CPAP) following nasal injury in a preterm infant. Arch. Dis. Child Fetal Neonatal Ed. 95, F142-F143 (2010).

38. Frerichs, I. et al. Patient examinations using electrical impedance tomographysources of interference in the intensive care unit. Physiol. Meas. 32, L1-L10 (2011).

39. Vogt, B. et al. Influence of torso and arm positions on chest examinations by electrical impedance tomography. Physiol. Meas. 37, 904-921 (2016).

40. Schmidt, B. et al. Indomethacin prophylaxis, patent ductus arteriosus, and the risk of bronchopulmonary dysplasia: further analyses from the Trial of Indomethacin Prophylaxis in Preterms (TIPP). J. Pediatr. 148, 730-734 (2006).

41. Schmidt, B. et al. Impact of bronchopulmonary dysplasia, brain injury, and severe retinopathy on the outcome of extremely low-birth-weight infants at 18 months: results from the trial of indomethacin prophylaxis in preterms. JAMA 289, 1124-1129 (2003)

\section{ACKNOWLEDGEMENTS}

We thank mothers and patients as well as staff at the University Hospital Zurich for their help. We thank Inez Frérichs for scientific input regarding the conversion of EIT data to clinically relevant $\mathrm{ml} / \mathrm{kg}$. Finally, we thank Cécile Keller for providing a picture of the fixation of the endotracheal tube in our unit.

\section{AUTHOR CONTRIBUTIONS}

L.P. and V.D.G. share the first authorship. L.P., V.D.G., J.T. and C.M.R. contributed to data collection; V.D.G., L.P. and A.D.W. performed data extraction and data analysis; V. D.G. and L.P. wrote the first draft of the manuscript; C.M.R. and D.B. supervised the project. All authors made substantial contributions to revising the article critically for intellectual content, and approved the final version of the manuscript.

\section{FUNDING INFORMATION}

V.D.G. was supported by a Start-Up Grant of the European Society for Pediatric Research and by a research grant of the EMDO foundation; J.T. was supported by a
Filling the Gap research grant by the University of Zurich. Open Access funding provided by Universität Zürich.

\section{COMPETING INTERESTS}

The authors declare no competing interests.

\section{CONSENT STATEMENT}

The Regional Ethics Committee of the Canton Zurich confirmed this study meets the requirements for quality assurance/audit projects (Req-2020-00929) and, thus, no informed consent is needed.

\section{ADDITIONAL INFORMATION}

Supplementary information The online version contains supplementary material available at https://doi.org/10.1038/s41390-021-01699-w.

Correspondence and requests for materials should be addressed to V.D.G.

Reprints and permission information is available at http://www.nature.com/ reprints

Publisher's note Springer Nature remains neutral with regard to jurisdictional claims in published maps and institutional affiliations.

(i) Open Access This article is licensed under a Creative Commons Attribution 4.0 International License, which permits use, sharing, adaptation, distribution and reproduction in any medium or format, as long as you give appropriate credit to the original author(s) and the source, provide a link to the Creative Commons license, and indicate if changes were made. The images or other third party material in this article are included in the article's Creative Commons license, unless indicated otherwise in a credit line to the material. If material is not included in the article's Creative Commons license and your intended use is not permitted by statutory regulation or exceeds the permitted use, you will need to obtain permission directly from the copyright holder. To view a copy of this license, visit http://creativecommons. org/licenses/by/4.0/.

(c) The Author(s) 2021 